\section{Poéticas Visuales mediadas por la tecnología. La necesaria opacidad}

\begin{abstract}
Resumen: Este trabajo encuadra las emergencias mediales contemporáneas en el marco de una nueva cosmovisión que asume como paradigma al cambio. Entiende al arte medial como testimonio de teorías científicas y epistemológicas contemporáneas. Frente al crecimiento exponencial de la cultura visual digital de masas, busca establecer la diferencia entre el fenómeno de la industria cultural digital contemporánea -denostada por su transparencia semántica y su valor puramente instrumental- y las artes mediadas por tecnologías, que habilitan la construcción del sentido. Analiza el impacto de la profusión de pantallas y medios para la convergencia digital sobre el sujeto contemporáneo y considera la existencia de un nuevo sujeto que improvisa una cultura audiovisual popular de masas. Propone como ejemplar de este estado de la cuestión, a la Video Instalación de la artista colombiana Clemencia Echeverri: Voz, Resonancias de la prisión (2005), obra que demuestra la injerencia del campo sonoro en el arte contemporáneo, habilitando al mismo tiempo una reflexión sobre la subjetividad creadora y el lugar de la mediación tecnológica en la gestión de un proceso de arte medial. Propone que el arte mediado por tecnologías pone en crisis criterios del arte mayoritario, consolidando un nuevo paradigma como emergente estético de la subjetividad contemporánea.
\end{abstract}

Palabras clave: Arte Contemporáneo - Arte Medial - arte y tecnologías - sujeto contemporáneo - video instalación.

[Resúmenes en inglés y portugués en las páginas 64-65]

${ }^{(*)}$ Profesional en Artes Visuales (Escuela Nacional de Bellas Artes Belgrano). Maestra en Artes Visuales (IUNA) e investigadora. Profesora Titular de Historia de las Artes Visuales y Teoría del Arte. Instituto Superior de Formación en Artes, Escuela de Artes Visuales, San Nicolás de los Arroyos, Buenos Aires.

\title{
Introducción
}

Pensar la subjetividad contemporánea requiere, como cualquier análisis de un fenómeno cultural, considerar su contexto, enmarcado a su vez en una determinada cosmovisión. Trataremos de trazar ese horizonte para ocuparnos de la subjetividad contemporánea y de forma singular, cómo ésta subjetividad se simboliza en emergentes visuales mediados por tecnologías. Proponemos que la subjetividad contemporánea se nutre de la concurrencia de dos factores: por un lado la ruptura final con el mecanicismo instaurado por la cosmovisión clásica, la cons- 
trucción de nuevos paradigmas epistemológicos y gnoseológicos, que dan lugar a la construcción de una nueva subjetividad y por el otro y en sincronía, se nutre del exponencial desarrollo instrumental tecnológico que gerencia una nueva cultura visual digital de masas que da lugar a una nueva iconosfera. Entendemos al sujeto social contemporáneo como protagonista de la tensión entre la lógica del código binario y la idea de un Dios que sí juega a los dados. Un sujeto que asume las tecnologías como "extensiones del cuerpo" y asiste al mismo tiempo a la incertidumbre que le plantea una cosmovisión que responde a sus preguntas con preguntas. Planteamos la necesidad de trazar un preciso linde entre la producción de obras de arte mediadas por tecnologías y los diseños visuales industriales destinados a la cultura de masas. Proponemos también que la obra de arte para ser legitimada como tal, deberá presentar opacidades, dejar huellas, resquicios de dudas para que el espectador, como sujeto receptor, preste su significación. Nos ocupamos solamente de obras de arte mediadas por tecnologías y buscamos en ese horizonte establecer la diferencia entre el fenómeno instrumental y transparente de las tecnologías para la ilusión visual de masas, en contraste con la opacidad que aporta a la misma tecnología, la mediación de la subjetividad creadora del artista.

Nos ocupará cómo impacta en la cultura contemporánea la naturalización de entornos digitales personales que habilitan el procesamiento de imagen y audio, artefactos minimizados en tamaño, maximizados en funciones, gadgets electrónicos para la información, comunicación, conectividad que en constante retroalimentación gestionan un escenario de medios para la captura, grabación y convergencia visual y sonora. Se despliega así un panorama de flujos de circulación de información (palabra, sonido, imagen) que trasciende lo instrumental y da lugar también a una construcción cultural. Proponemos que este fenómeno cultural contemporáneo encuentra su correlato en la existencia de disciplinas del arte con soportes tecnológicos que habilitan al artista a hacer de ellas herramientas creativas que hacen posible discursos interactivos, simultáneos, superpuestos, móviles, sonoros, concebidos para un espectador que asume también un nuevo rol frente a la obra de arte.

Entonces, los dos factores en tensión que se proponen son, por un lado la cosmovisión que introduce criterios de caos, complejidad y probabilidad y por el otro el amplio despliegue de una cultura tecnológica visual de masas. Campo gnoseológico uno, instrumental el otro que convive en el plano de una nueva subjetividad creadora y una nueva subjetividad del potencial espectador contemporáneo, gestionándose un también nuevo vínculo entre uno y otro.

Teniendo en cuenta este panorama planteamos que las formas de arte mediadas por tecnologías, en adelante "mediales", como emblemáticas de la contemporaneidad, capaces de cuestionar la categorización y entidad de la obra de arte, que fue históricamente un "artefacto", dando lugar a un horizonte de nuevos códigos, herramientas, medios y saberes, con nuevas formas de idear, producir, visibilizar, conservar, recibir y protagonizar la imagen y el sonido. Entendemos al mismo tiempo que la diferencia entre las artes mediales y el videojuego o demás emergentes visuales tecnológicos industriales y de masas, estriba en el proceso por el cual se logra la opacidad del arte, que permite nublar la transparencia instrumental que es sin embargo el propósito final del videojuego y la propiedad principal de las tecnologías para la cultura de masas, concebidas para el entretenimiento y que habilitan la conducta operacional pura.

Analizaremos una obra en particular: la Instalación sonora "Voz/Resonancias de la prisión" (2005) de la artista Colombiana Clemencia Echeverri, que como video instalación, nos permitirá ejemplificar el proceso de opacidad que amerita la construcción de una obra de arte. 
"Voz/Resonancias de la prisión" es una obra que consideramos relevante en el marco del arte contemporáneo en general y singularmente en el del arte mediado por tecnologías. Obra que entendemos paradigmática por poner en crisis criterios clásicos de lo que hemos dado por entender como obra de arte, subvirtiendo el tradicional lugar del dominio de la imagen -en lo que llamábamos Artes Visuales- por la presencia espectral del campo sonoro. Elegimos a Clemencia Echeverri como artista prominente de nuestra cultura latinoamericana, porque en su producción concilia la tensión entre las problemáticas sociales contemporáneas y el uso de medios de alta tecnología para la ideación y realización de sus obras.

\section{Cosmovisión moderna y emergencia visual}

Pensemos brevemente al sujeto moderno frente a la construcción de su realidad: se percibe amo de su pensamiento, dueño de una razón que le permite observar el mundo suponiéndose escindido de él. Neutro en la deducción de sus especulaciones el sujeto moderno se sitúa frente al objeto observado sintiéndose dotado de una mente capaz de domeñar sus ideas tanto como la naturaleza. Dice Llamazares:

El incipiente hombre moderno se siente dueño de sus capacidades y por lo tanto, más seguro. Son sus nuevas habilidades técnicas y su propia racionalidad los instrumentos que lo habilitan para la conquista del mundo que ahora se abre ante él como un territorio a explorar y consecuentemente, dominar. (Llamazares, 2011, p. 79).

La visión moderna del mundo está predeterminada por el orden que se suponía regía un cosmos que no necesitaba del sujeto (nosotros los hombres y mujeres) para interpretarlo. Llamazares elige como metáfora de la cosmovisión moderna la imagen de un reloj, que pauta las horas, minutos y segundos de un cosmos preciso, metódico, regido por leyes tan mecánicas como las que permiten la medición del tiempo.

\section{Paradigma moderno e imagen}

Según Gubern (1996) la imagen es un "artefacto social”. El "artefacto" creado por la subjetividad moderna asume la estructura de una total disciplina. Del siglo XV al XIX el orden visual de la modernidad es icónico, una "imagen espejo". Durante la modernidad son pocos los movimientos que por reacción, escapan al rigor del número en la construcción de la imagen con premisas matemáticas o geometrías.

Pitágoras (...) es el primero en sostener que el principio de todas las cosas es el número. Los pitagóricos sienten una especie de terror sagrado ante el infinito y todo aquello que no puede reducirse a un límite, y por eso buscan en el número la regla capaz de limitar la realidad, de proporcionarle orden e inteligibilidad (Eco, 2004, p. 61). 
El número gobierna explícita o implícitamente el orden visual moderno. Los modelos ideales de Leonardo Da Vinci, los tratados de perspectiva de Piero de la Francesca o Luca Paciolli, el tratado de proporciones de la figura humana de Alberto Durero ${ }^{1}$, expresan el correlato entre las leyes que gobiernan la imagen y las que rigen el orden cósmico en la visión moderna, cosmos que consideran regular y predecible, de funcionamiento mecánico.

La ciencia auxilia al orden visual con leyes de geometría y cálculos matemáticos que proporcionan la buscada estabilidad de las formas, como estable era su universo ${ }^{2}$. La iconicidad moderna da testimonio de la separación de sujeto y objeto, se sitúa frente al mundo, no dentro de él. Necesitará así de algún sistema de representación nuevo para mostrar esa escisión. Espeja entonces, por medio del claroscuro y del artificio de la perspectiva Albertina, el mundo visible que consigue simular mediante la reproducción mimética de las cosas para brindar la ilusión de un espacio tridimensional sobre la superficie bidimensional de la representación. El Renacimiento entronizó como soporte al cuadro o tableau que cobrará en Occidente un valor "universal”. El cuadro, al que Octavio Paz refiere como "obra de arte sentada en su pedestal de adjetivos" (Paz, 1973) es un artefacto tangible, capaz de ser fácilmente llevado de un sitio a otro, cambiar de dueño y ser objeto del mercado capitalista destinado al príncipe o al burgués. Se concibió formalmente para pender de un muro y ser observado en actitud pasiva. El predominio político y cultural europeo extendido territorialmente, prolongó en el tiempo a este soporte favorito de artistas y consumidores, instalándose en el imaginario colectivo como sinónimo de emergencia visual, como el "artefacto social" funcional al paradigma epistemológico y sociocultural de la modernidad.

\section{Dios sí juega a los dados. Paradigmas epistemológicos contemporáneos}

El paradigma clásico se resquebraja a finales del siglo XIX mostrando sus primeras grietas cuando, desde la misma ciencia asistamos a la búsqueda y luego hallazgo de principios que no convalidan la certidumbre de la cosmovisión moderna ${ }^{3}$. Gruner (1997) llama a este período "modernidad crítica". Llamazares lo denomina "la caída de la certeza" a la que sucede el siglo XX con "la crisis de la razón". Se despierta en Occidente la conciencia de un nuevo orden o la posibilidad de un desorden. Desde las primeras décadas del siglo se desata un debate en el campo científico ${ }^{4}$ en el que físicos, químicos y filósofos asisten al derrumbe de la cosmovisión moderna. "En lugar de la certeza había que admitir la incertidumbre. Confiaba -decía Niels Bohr- que describir leyes era abolir lo arbitrario; pero a poco que siguiera, la ciencia se convertiría en un laberinto a cuyo extremo lo esperaba un nuevo Minotauro: el azar" (citado por Massuh, 1990, p. 158). Los enunciados científicos dan lugar a la construcción de nuevos paradigmas epistemológicos, gnoseológicos y filosóficos que permiten la condición posmoderna y lo que se dio en llamar la caída de los "grandes relatos", según Lyotard (1991): razón, historia y progreso. Se despertaba con el siglo XX una nueva subjetividad. Einstein sin embargo no admitió la posibilidad de la aleatoriedad del comportamiento de los sistemas y dice "...era como que la tierra hubiese sido quitada debajo de mis pies, sin ningún cimiento firme a la vista, sobre el cual poder construir" (citado por Llamazares, 2011, p. 229) y en oportunidad de una charla con Bohr sentenció su: "Dios no juega a los dados con el Universo".

Los postulados que formatean la cosmovisión contemporánea resultan tan generosos como 
temerarios. Generosos porque nos habilitan a liberarnos del corsé del pensamiento moderno modelado en el decurso histórico. Temerarios porque obligan a tomar distancia de criterios de objetividad, causalidad y predictibilidad que distinguen al pensamiento moderno, tan objetivo y ordenado como sus emergentes visuales. La nueva subjetividad es huérfana o acaso se concibe como parte de una totalidad imposible de disciplinar como el cosmos moderno. Somos parte de un mundo que construye una cosmovisión que se asume aleatoria, impredecible, probabilista, inestable, en la que "una ontología del ser" da lugar a una ontología del "devenir, y por tanto, de la valoración de lo fijo a la celebración del cambio y la transformación” (Llamazares, 2011, p. 325). En ese contexto muda el vínculo sujeto/objeto como entidades divididas para consolidar el criterio de un nuevo sujeto integrado a la totalidad en "un proceso en el que participamos, no como una cosa externa que debemos adquirir. Conocer no es aprehender una realidad objetiva y externa e interiorizarla en una subjetividad vacía y aséptica. El conocimiento como proceso participativo es un encuentro transubjetivo, por tanto, comunicable, que acontece más allá de la razón y la fe, como una dinámica de apertura recíproca en la que sujeto y objeto se vinculan íntimamente y por lo tanto, implica una muta transformación” (Llamazares, 2011, p. 42). Volveremos sobre este párrafo al referirnos más adelante a la interfaz creador/espectador.

\section{Después de la modernidad. Puesta en crisis de la categoría de obra de arte.}

El siglo XX se abre para las estéticas de Occidente con el debate figuración/abstracción, "superficie/representación” (Menna, 1975). Las Vanguardias rompían con quinientos años de iconicidad. En la sucesión de "ismos" durante la primera mitad del siglo se protagonizó el provisorio ${ }^{5}$ abandono del realismo icónico. Con las distintas formas de abstracción asistimos a un giro artístico que calificamos de formal, porque no se pone en duda el valor estatutario del cuadro como soporte, por lo que no asistimos aún a un quiebre cultural con respecto a la categorización de obra de arte. En esos años, sin embargo, un artista como Marcel Duchamp subvierte principios legitimados aún por las Vanguardias, introduciendo como "arte" al primer ready-made: "Rueda de Bicicleta" (1913). Enteramente ajenas a la provocación Dadá, las artes mediales tienen no obstante algo en común con el ready-made: eluden la "manufacturación" de la obra, son factibles de multiplicación, son esquivos al mercado, diluyen -como la rueda de bicicleta de la cual Duchamp hizo distintas versiones- el borde entre original y copia. Puntos radicales de inflexión en los criterios estatutarios de lo que tradicionalmente se juzgó como obra de arte.

Desde los primeros gráficos realizados por computadoras por Ivan Sutherland en 1962 en el Lincoln Laboratory del MIT (dato aportado por Darley, 2002) a hoy, la cultura visual digital recorrió caminos que no permiten la categorización de obra de arte ni contribuyeron a dar crédito a las tecnologías entre los artistas analógicos que entendieron a ese tipo de imágenes como puramente instrumentales. Este juicio crítico fue potenciado por la masividad alcanzada por el desarrollo de la amplia familia del videojuego y la industria cinematográfica de entretenimiento con uso de efectos especiales, también y necesariamente situados frente y no junto al cine de arte. Salir de ese lugar de imagen significante sin significado es lo que da al arte medial su estatuto de arte. 


\section{Baudrillard y la trasparencia tecnológica}

Llegado este punto es necesario convenir qué vamos a legitimar como obra de arte mediada por tecnologías: validaremos como en cualquier otra disciplina analógica, su opacidad. Opacidad es la voz con que adjetiva Ravera a la cualidad del texto artístico

...el sentido no puede desprenderse de los signos punto por punto, en correspondencia de término a término. Se organiza a partir de la relación entre los signos, oblicuamente, creciendo como en los vericuetos de un inmenso paño labrado al revés, mientras revolotea entre las palabras surgiendo del movimiento total de éstas, en y desde el silencio (Ravera, 2000, p. 34).

La transparencia, lo inmediato, lo operacional, no es condición de la obra de arte que debería necesariamente ser opaca, penetrar la superficie y habilitar al espectador a leer la obra como un tejido y a preguntarse por quéy para qué, sin que el cómo le sea relevante. Es como mirar a través de una ventana, lo que importa es el paisaje, no el vidrio que nos separa de él. La cultura visual digital de masas es en su funcionalidad, un enorme cómo, un vidrio translúcido a través del cual no podemos ver, quedando nuestra vista atrapada en la superficie.

La tecnología y su facilidad instrumental se sitúan en las antípodas de la opacidad, del retardo que pide la obra de arte. Dicho esto, necesitamos entonces exponer en particular qué queremos decir por obra mediada por tecnologías y analizar cómo es posible para el artista medial desvanecer su transparencia. Baudrillard, cuyo equipaje de ideas ha permitido tomar conciencia de las trampas que pueden gerenciar los medios de masas y sus simulacros, anatemiza las tecnologías con enunciados como: "Intentan persuadirnos de la buena finalidad ineluctable de la técnica", a la que atribuye "un estado de inteligencia operacional pura y por lo tanto desilusión radical del pensamiento" (Baudrillard, 1996, pp. 32-33). Es igualmente crítico de Duchamp a quien condena por haber llevado al arte (con su ready-made) una "hiperrealidad inefable", crimen que asocia también al uso de tecnologías. Consideramos importante tomar posición frente a estos criterios. Baudrillard no hace explícita una distinción entre los "media" que condena y la posibilidad de que la misma tecnología dé lugar a expresiones con el mismo valor de significado que cualquier obra de arte analógica. Medios, televisión, cámaras y pantallas que emiten y reproducen sin conciencia, imagen en tiempo real y toda la parafernalia que habilitan los aparatos electrónicos, facilitan ciertamente las "perversas" estrategias de manipulación visual y comunicacional con instrumentos para la construcción de simulacros, que como la trampantojo, tienen un fin puramente operacional, son transparentes, asesinos de cualquier posibilidad poética. 


\section{Opacidad y arte medial. Usuario/espectador/gerenciador}

Crítica frente al despliegue contemporáneo de tecnologías Ravera dice:

En una sociedad de avanzada tecnología como la nuestra, con un progreso tan acentuado de la informatización, se tenderán a imponer los mensajes de veloz decodificación. La condición de la producción de la significación va a ser, por consiguiente, una traducibilidad directa. Lo que se traduce sin residuos, sin resto. Ya nos encontramos aquí con un problema de fondo. El que afecta al arte (Ravera, 2000, p. 190).

Entendemos que el arte necesita dejar resto, que es necesariamente un canal de significación que necesita ofrecer la posibilidad de una paulatina decodificación, "opacidades" que le permitan tomar distancia de la inmediatez de la respuesta operacional pura. Darley (2002, p. 198) se refiere a la cultura visual de masas habilitadas por los medios digitales, adjetivándolas como "juego de superficie" porque no hay, en las acciones o sensaciones que se promueven en el usuario, posibilidad alguna de facultarlo para una lectura hermenéutica, en ausencia de toda posibilidad de tiempo y distancia para la interpretación. Al decir de Jameson (2002) son meros "significantes", no significados.En los márgenes de la información, en los márgenes del mensaje de veloz decodificación, ubicamos a las obras de arte mediadas por tecnologías, en las que la transparencia operacional es opacada por el artista y destinada a un espectador capaz de dotarlas de sentido. Sentido más necesario hoy que nunca en el campo del arte, en el marco de una cosmovisión en la que Dios efectivamente juega a los dados ${ }^{6} \mathrm{o}$ acaso lo que parece azaroso tenga un orden que la física aún no pudo descifrar. La cosmovisión contemporánea presenta una complejidad abrumadora y el arte contemporáneo también.

Las obras de arte medial pueden converger en medios y estrategias con los sistemas tecnológicos masivos para el entretenimiento, pero el trabajo del artista consiste necesariamente en domeñar la tecnología para que el espectador estrene ante ellas una nueva actitud. La tecnología es solamente el instrumento, el cómo que requiere de ingenierías varias. Dice Gubern "se ha fundado una nueva antropología de lo visible y está solicitando la emergencia de la nueva figura del artista-ingeniero, como lo fue Leonardo en el Quattrocento" (Gubern, 1996, p. 149). La problemática del arte es la misma para un artista que para el otro, sea analógico o medial. No se trata entonces de la promiscuidad de lo hiperreal digital e instrumental, sino de la mediación poetizante y significante de un artista que incorpora tecnologías como extensión de su mente, con el necesario distanciamiento que aporta lo sesgado, creando los vericuetos para el tejido de una suerte de inmenso paño labrado que será visto del revés - palabras de Ravera-y permitirá al espectador interrogarse para qué y por qué, el cómo viene de suyo, es parte del oficio.

Las distintas disciplinas mediales consolidan un nuevo giro cultural poniendo en crisis la categoría de obra de arte como artefacto, en obras que en su despliegue visual y/o sonoro son dato que se hace visible o audible por diversidad de canales, espacios, calidades, cualidades, tamaños, en función de relatos que pueden o no ser interactivos, requiriendo en tal caso la intervención del espectador que modifica o da lugar a la escena. El espectador/gerenciador no puede sin embargo perforar los límites de lo que el artista ha integrado al sistema. En la interacción electrónica, como en la interfaz entre un espectador y el cuadro, no hay intersubjetividad porque 
uno de los dos polos no es un sujeto. En ese punto se mide la estrategia del creador medial, el ser capaz de significar en la elección de la interfaz, que como tal habilitará con un racional desarrollo teórico de su sistema audioperceptivo, la aleatoriedad de las decisiones y acciones de un espectador/gerenciador.

\section{Instrumento y cultura del instrumento}

Si entendemos la imagen como objeto social, es necesario que nos preguntemos cómo está constituida la iconosfera contemporánea. Somos protagonistas de un exponencial desarrollo de medios visuales de masas (videojuego y cine de efectos digitales) que "educan" en la dependencia de lo hiperreal -cuerpo sin alma-capaz de construir en el sujeto la necesidad de "inmersión" en la imagen. El videojuego gestiona al mismo tiempo la transparencia de un tipo de interacción donde no hay más que un estímulo y una respuesta igualmente operacional posible. Por otro lado asistimos a otro tipo de tecnologías, las de conectividad y convergencia (teléfonos celulares o todo tipo de dispositivo "inteligentes") que familiarizan y naturalizan en el usuario la captura de imagen/sonido y la convergencia social a partir de ellos. Difícilmente estos medios puedan gestionar algo más que pura conectividad, pura información transparente. Sin embargo la práctica instrumental de entornos digitales da lugar a la cultura de la respuesta, efectiva, pero sin decodificación. Se naturalizan conductas, respuestas automáticas con alto grado de eficacia. Se activa una cultura de medios electrónicos de masas en los que la acción/reacción inmediata es constitutiva. En consecuencia, la subjetividad de un potencial espectador está hoy impactada por el estímulo visual/sonoro y la inmediata, hábil y acertada respuesta. Por seiscientos años el cuadro no necesitó más que ser contemplado, ajeno a sensores o conexión física o electrónica alguna con el espectador. El pintor no tiene, como el artista medial, un monstruo que enfrentar como la industria audiovisual de masas. El desafío de esta especie de artistas estriba en la cuidada arquitectura de su obra capaz de arbitrar la construcción de significado. El videojuego está tan cerca del arte medial como el trampantojo de una pintura icónica.

\section{"Voz/resonancias de la prisión"}

Con el fin de ejemplificar este texto elegimos una obra medial, Video Instalación interactiva, para acompañar las conclusiones. Se trata de "Voz/resonancias de la prisión"7 de la artista Clemencia Echeverri, Colombia, 2005. La obra será nombrada en adelante con la primera parte de su título. La instalación fue concebida específicamente para las tres salas del Museo Nacional de Colombia, Bogotá y se exhibió luego como "Actos del habla" en el Museo de Arte de la Universidad Nacional, Bogotá, Colombia, 2009. "Voz" dio lugar a "Voz Net"8, 2008 como versión de Net-Art.

Nos proponemos analizar cómo la artista, en una obra donde las tecnologías son constitutivas, logra opacar su transparencia. "Voz" no es por cierto un mensaje de veloz decodificación sino un relato velado de alta capacidad simbolizadora y de significación latente, expresadas en la construcción de un espacio espectral, por medio de la instalación en sitio del resultado de un proceso de videocaptura, videoproyección, captura sonora, emisión sonora, acción y perfor- 
mance, en función de la arquitectura de un dispositivo sonoro y visual interactivo.

En 2003 Echeverri realiza una serie de visitas a prisiones. Se trata de entrevistas mantenidas con prisioneros colombianos presos en diferentes cárceles de Inglaterra y una cárcel de mujeres en Colombia. El proceso creativo de "Voz" comienza a tomar cuerpo. Ajeno a la forma o el fin de la documentación periodística, Echeverri propone a las instituciones la realización de talleres en los que los prisioneros y prisioneras pudieran expresarse, dejar oír sus voces. Con su anuencia la artista registra con diferentes tecnologías “...voces sin niñez, sin padres, sin afectos, sin educación, llenas de maltrato y de humillación” (Echeverri, 2009, p. 104). Seguirá al registro de voz la selección y clasificación de los testimonios que luego en la edición, se opacan para que el relato pierda su cualidad documental. Se idea y construye un sistema de sensores que por medio de una interfaz se activan ante la presencia del espectador/escucha. Los parlantes solamente emitirán sonido ante la cercanía de quien se disponga a oír las voces, de lo contrario reinará el silencio en la sala. Las voces de los presos se editan en fragmentos estructurando un patrón de construcción sonora con voluntad solamente poetizante, capaz de tejer una inmaterial trama dentro del espacio donde se alojarán los parlantes y crear la ilusión de que el espacio vacío está sin embargo atravesado por fantasmales líneas de voz. Esta arquitectura sonora se erige luego en un sitio elegido para ese fin: las salas del primer piso del Museo Nacional de Colombia, que durante 70 años fuera la Penitenciaría Central de Cundinamarca.

Las salas se intervienen también visualmente. En la pared posterior de cada una de ellas y espejando los espacios físicos de las galerías, se proyecta un video que exhibe la imagen del mismo espacio. Un tramo de sala se prolonga así en otro espacio que lo reproduce, que se ve pero no se visita ni habita. En un monacal blanco y negro que remite al pasado, el video proyecta la imagen de las salas vacías o con uno u otro espectador que se detiene en una u otra columna para asistir al acto íntimo del confesionario, a oír las voces emitidas por los parlantes, activados por la presencia del escucha. El video también trae a las monumentales salas del actual museo, la imagen espectral del deterioro de las viejas barracas que alojaban a los prisioneros o acaso la imagen del muro en los que se dejó grabada una señal de presencia. La proyección altera la topografía y la linealidad del corredor se ve infinita, espejada y prolongando el lugar físico de gruesas columnas y bóvedas por medio del espacio inmaterial de la imagen videográfica. En la arquitectura de "Voz" hay más inmaterialidad que artefacto. Sólo piso, columna y bóveda tienen corporeidad. Reinan el vacío y el silencio solamente interrumpido por la casual activación de un sensor que habilita la escucha de una voz. En la imagen proyectada vemos presidiarios de entonces, aunque son de hoy los que se oyen. Ambos ausentes porque "Voz" es el registro de una ausencia. Dispuestas de dos en dos, en las gruesas columnas de las salas y si hay un oído que la escuche, la voz de los ausentes es presente en el tácito acto de su habla. Entre una columna y otra, segmento de relatos, hilos de voz.

Decía Ravera que era necesario que el arte fuese capaz de permitir que el espectador relacione signos, que ofrezcan restos. Entendemos que es lo que Echeverri ha erigido: una construcción espacial, sonora y visual donde los tres elementos en concierto son lugar, tecnologías, imagen y sonido, todos necesarios en función de la entidad del proyecto. También decía Ravera que la obra de arte se concibe para ser interpretada "oblicuamente, creciendo como en los vericuetos de un inmenso paño labrado al revés, mientras revolotea entre las palabras surgiendo del movimiento total de éstas, en y desde el silencio" (Ravera, 2000, p. 34). Proponemos que es no solamente posible, sino necesario prestar las palabras de esta autora a una obra como "Voz". Vi- 
deo Instalación, obra de arte mediada por tecnologías -videográficas y sonoras- suma de ideas, acciones, talleres, encuentros, sentimientos que se desplegaron en el espacio físico (o virtual en el caso de la versión Voz-Net) y que ontológicamente son dato sostenidos en archivos. Obra sólo posible por el uso de tecnologías en función de la capacidad simbolizadora de cada uno de los concurrentes de un sistema no solamente instrumental, sino semántico. Citamos "Voz-Net" porque alude a una de las características de la obra medial que nos ocupa: su factibilidad de asumir otro soporte, si "Voz" es Instalación, "Voz-Net" es Net Art, donde la interacción con el espectador tiene otro tipo de interfaces y otro tipo de espacialidad.

Baudrillard sostenía que el uso de tecnologías era sinónimo de "radical desilusión del pensamiento". Sin la mediación de un proceso de creación artística las voces del presidio serían enunciados vaciados de sentido estético, comunicación pura, transparencia operacional. No se trata de entrevistas en un trabajo de campo y su posterior análisis documental. Se trata de la necesaria opacidad de la obra de arte mediada por las tecnologías, sin las cuales la obra no tendría su entidad. Los restos, los resquicios serán oídos y, conciencia, imagen, pasado, presente, ausencia, soledad, niñez, irreversibilidad del tiempo y de los actos, encierro, culpa, castigo, prejuicio, presidio y todos los etcéteras posibles (u otros) serán significados que preste el espectador.

\section{Concluimos}

Nos propusimos pensar la subjetividad contemporánea entendiendo que ésta se dirime en la tensión entre una nueva cosmovisión que borró la regularidad mecanicista del pensamiento clásico y una cultura visual digital de masas de gran impacto instrumental con un desarrollo exponencial en los últimos treinta años. Entendimos que la conectividad electrónica es de veloz decodificación sin la opacidad que requiere el horizonte del arte. Que los sistemas tecnológicos en sí no dan como resultado más que una inteligencia nublada por la inmediatez, por el estímulo puro sin conciencia. Las tecnologías de las que hoy disponemos, como extensiones de cuerpo y mente, integran nuestra iconosfera. Retratan la contemporaneidad del mismo modo que la regularidad y orden de la icnografía clásica daba testimonio de su cosmovisión mecanicista. El artista se inmiscuye entre las máquinas, las hace propias, aprende su lenguaje y sus ingenierías. $\mathrm{Y}$ es entonces cuando la tecnología cobra la opacidad que borronea toda transparencia.

Nos propusimos volver sobre un párrafo de Llamazares donde se refería a los nuevos paradigmas científicos y a la manera en que éstos nos invitan a la "celebración del cambio y la transformación", principios que resultan familiares a la obra interactiva que se concibe para un espectador que la activa y la vivencia aleatoriamente. No hay entre obra y espectador transubjetividad, si la hay -obra mediante- entre el artista y quien ve y escucha. Sin ese espectador "Voz" no tendría voz.

Y porque entendemos que es muy posible que Dios juegue a los dados, la subjetividad contemporánea seguramente hoy más que nunca, es interrogada por temáticas que atraviesan problemáticas sociales, como la obra elegida como emergente visual del arte medial y como emblemático emergente también de la subjetividad contemporánea. La problemática social ya 
fue interrogada con similar respuesta: la modernidad crítica y/o asediada del siglo XIX que tuvo su emergencia artística en el Realismo y pintaba, sobre el analógico lienzo icónico al Hombre a quien empezaban a morírsele los dioses, mientras el mundo cambiaba ante sus ojos y su manos se veían suplantadas por la máquina.

La subjetividad contemporánea encuentra un claro emergente visual en la obra medial donde el cómo es solamente el sostén de los por qué y para qué. Si como dice Baudrillard (1996, p. 47) “... la más alta definición del medio corresponde a la más baja definición del mensaje”, el artista que intermedia sus obras por el uso de tecnologías habilitará -como ha sucedido siempre en la arqueología de la imagen- según su talento, la elipse necesaria para alcanzar el más alto estándar de significación.

\section{Notas}

1. Los textos citados son: De perspectiva pingendi, Piero de la Francesca; De Divina proportione, Lucca Paciolli y Tratado de las proporciones del cuerpo humano, Alberto Durero.

2. Triángulo "sublime", número de oro, espiral logarítmica, serie de Fibonacci, pentagrama, etc. 3. Freud, Darwin y Nietzsche asestan un duro golpe a la cosmovisión moderna.

4. 1900 Ley de Planck; 1905 Einstein enuncia la Teoría de la Relatividad; 1927 Heisenberg enuncia el Principio de Incertidumbre; 1920-1930 Niels Bohr, Erwin Schrödinger, Jon von Neumann. Ilya Prigogine: Teoría cuántica y exploración del mundo subatómico. 1979/1988 Ilya Prigogine, Isabelle Stengers, el tiempo como un continuum. Datos de Massuh (1990).

5. El gusto por el realismo, potenciado a su máxima expresión, es retomado por la cultura de masas, en lo que Darley (2002) llama "fotorealismo simulado" o "juego de superficie", estética dominante de los videojuegos y de las películas de entretenimiento con efectos especiales, con su mayor exponente en el cine tridimensional o la ilusión realista de la animación por motion capture.

6. Proponemos en este margen, que en un tiempo en el que no hay verdades absolutas, ausente de grandes relatos, es necesario que el arte aporte sentido, en oposición a los Situacionismos que persisten, al cabo de décadas, en la ruptura de algo ya largamente roto y suman por el contrario dosis de sinsentido.

7. Voz: video proyección en cada una de las 3 salas que forman el panóptico del Museo. Sonido mono en 1 sala, sonido Dolby 5.1 en las demás. MAX NSP. Sala gris oscuro. Video NTSC y PAL. Las dimensiones varían según el espacio de instalación. Edición de 5 copias. Créditos: Investigación, Dirección y sonido: Clemencia Echeverri. Interfaz de sonido Daniel Prieto. Interactividad: Martha Patricia Niño. Edición de video: Boris Terán. Montaje y asistente de producción: Oscar Moreno. Cámara: Santiago Martínez. Ver: http://www.clemenciaecheverri.com/webcastellano/index.php/proyectos

8. Versión de "Voz" para Net-Art en CD ROM interactivo, realizada con el auspicio del Arts Council de Londres como "No longer empty project" y presentada en la Bienal de Liverpool. Inglaterra (2010). Ver la misma página y vínculo Web. 


\title{
Referencias Bibliográficas
}

Baudrillard, J. (1996). El crimen perfecto. Barcelona: Anagrama. Colección Argumentos.

Darley, A. (2002). Cultura visual digital. Espectáculo y nuevos géneros en los medios de comunicación. Buenos Aires: Paidós Comunicación 139 Cine.

Eco, U. (2004). Historia de la Belleza- a cargo de Umberto Eco. Barcelona: Lumen.

Echeverri, C. y otros (2009). Sin Respuesta. Universidad Nacional de Colombia. Bogotá.

Jameson, F. (1992). Signatures of the Visible. Londres, New York: Routledge.

Lyotard, J. (1991). La condición posmoderna. Buenos Aires: Editorial Rei.

Gruner, E. (1997). Seminario: Modernidad Posmodernidad. ¿Un debate superado? Universidad Nacional de Rosario. Facultad de Ciencias Políticas 1998.

Gubern, R, (1996). Del bisonte a la realidad virtual. La escena y el laberinto. Barcelona: Anagrama. Colección Argumentos.

Llamazares, A. (2011). Del reloj a la flor de loto. Crisis contemporánea y cambio de paradigmas. Buenos Aires: Editorial Del Nuevo Extremo.

Massuh, V. (1990). La flecha del tiempo. En las fronteras comunes a la ciencia, la religión y la filosofía. Buenos Aires: Editorial Sudamericana.

McLuhan, M. (1966). Comprender los medios de comunicación las extensiones del ser humano. Barcelona: Paidós.

Menna, F. (1975). (Trad. 1977). La acción analítica en el arte moderno. Figuras e íconos. Barcelona: Gustavo Gilli.

Paz, O. (1973). Apariencia desnuda. La obra de Marcel Duchamp. México DF: Editorial Era.

Ravera, R. (2000). Estética y semiótica. Rosario: Editorial Fundación Ross.

\section{Recursos Electrónicos}

Clemencia Echeverri. Disponible en: http://clemenciaecheverri.com (Consultado el 1-1-2012). Naum Paix. Disponible en: http://www.paikstudios.com/ (Consultado el 7-1-2012).

Teoría cuántica. Disponible en: http://www.tendencias21.net/La-Teoria-Cuantica-una-aproxi macion-al-universo-probable_a992.html (Consultado el 6-1-2012).

\begin{abstract}
Summary: This paper frames the contemporary media emergencies under a new worldview that assumes a paradigm change. He understands the media art as a testimony of contemporary scientific and epistemological theories. Faced with the exponential growth of digital visual mass culture, seeks to establish the difference between the phenomenon of contemporary digital culture industry - reviled by their semantic transparency and purely instrumental value - and the arts mediated by technologies that enable the construction of meaning. Analyzes the impact of the profusion of screens and digital convergence media for the contemporary subject and considers the existence of a new subject that improvises a popular mass media culture. The article proposes as an example, the video installation of the Colombian artist Clemencia Eche-
\end{abstract}


verri: Voice, Echoes of the prison (2005), a work that demonstrates the interference of the sound field in contemporary art, enabling both a reflection on the creative subjectivity and place of technological mediation in managing a process of media art. Proposes that art mediated by technology puts a strain on mainstream art criteria, consolidating a new paradigm as emerging aesthetic of contemporary subjectivity

Key words: art and technology - Contemporary Art - contemporary subject - Media Art - video installation.

Resumo: $\mathrm{O}$ trabalho enquadra as emergências mediais contemporâneas no marco de uma nova cosmovisão que assume como paradigma ao cambio. Entende à arte medial como testemunha das teorias científicas e epistemológicas contemporâneas. Frente ao crescimento exponencial da cultura visual digital de massas, procura estabelecer a diferença entre o fenômeno da indústria cultural digital contemporânea e as artes mediadas por tecnologias, que habilitam a construção de sentido. Analisa o impacto da profusão de telas e médios para a convergência digital sobre o sujeito contemporâneo e considera a existência de um novo sujeito que improvisa uma cultura audiovisual popular de massas. Propõe como exemplar esse estado da questão, à Vídeo Instalação da artista colombiana Clemência Echeverri: Voz, Ressonâncias da prisão (2005), obra que demonstra a ingerência do campo sonoro na arte contemporânea, habilitando ao mesmo tempo uma reflexão sobre a subjetividade criadora e o lugar da mediação tecnológica na gestão de um processo de arte medial. Propõe que a arte mediada por tecnologias põe em crise critérios da arte majoritária, consolidando um novo paradigma como emergente estético da subjetividade contemporânea.

Palavras chave: Arte Contemporânea - arte e tecnologias - Arte Medial - sujeito contemporâneo - vídeo instalação. 